\title{
Determination of Mode II Interlaminar Fracture Toughness of CFRP Composites using Numerical Simulations
}

\author{
Frantisek Sedlacek $^{1, a}$, Tomas Kalina ${ }^{1, b}$ and Karel Raz ${ }^{1, c}$ \\ ${ }^{1}$ University of West Bohemia, Faculty of Mechanical Engineering, RTI - Regional Technological \\ Institute, Univerzitní 22, 306 14, PIzeň, Czech Republic \\ afsedlace@rti.zcu.cz, btkalina@rti.zcu.cz, ${ }^{\mathrm{a}} \mathrm{kraz} @$ rti.zcu.cz
}

Keywords: Composite Materials, Fracture toughness, ENF Test, Mode II, Numerical Simulation.

\begin{abstract}
This paper deals with a numerical simulation of the interlaminar fracture toughness of woven carbon fibre reinforced polymer. Composite materials are increasingly used for their unique properties in many branches of engineering. They are also used for flexible components such as springs, couplings, etc. The strength of these parts must be determined not only in terms of their intralaminar properties but also in terms of their interlaminar properties. This paper provides a methodology for determining the main parameters for Mode II interlaminar fracture toughness using numerical simulation. End Notch Flexure (ENF) specimens were created for fitting fracture toughness parameters of the laminate according to ASTM standards. Three point bending ENF tests were carried out on a Zwick/Roell Z050 machine. The numerical simulation was created in Siemens Simcenter 12.0 using NX Nastran nonlinear solver. The results from the numerical simulation correspond to those from the experimental test with an accuracy of $4 \%$.
\end{abstract}

\section{Introduction}

Two basic types of failure are recognized in composite laminate structures; intralaminar and interlaminar failure. Interlaminar failure (delamination) is one of the main weaknesses of composite laminates with long fibres [1]. Delamination in laminated composite structures usually originates from discontinuities such as cracks in the matrix or the presence of free edges [2]. The principles of linear elastic fracture mechanics have been extended to composite materials to characterize delamination (interlaminar fracture) [3]. Interlaminar damage can be divided into three main modes of fracture: mode I (opening mode), mode II (in-plane shearing) and mode III (anti-plane shearing). Finding the parameters of each mode is still difficult. This paper deals with finding the main parameters of mode II (especially fracture toughness) using numerical simulation based on the finite element method.

\section{Interlaminar Damage Interface}

In this case a damage interface (interlaminar) model for predicting delamination based on the cohesive elements approach was used [4]. This model considers three damage variables $\left(d_{I}, d_{I I}\right.$ and $\left.d_{I I I}\right)$ for determining the elastic strain $E_{D}$, see Eq. 1.

$$
E_{D}=\frac{1}{2}\left[\frac{\left\langle\sigma_{33}\right\rangle_{-}^{2}}{k_{3}^{0}}+\frac{\left\langle\sigma_{33}\right\rangle_{+}^{2}}{k_{3}^{0}\left(1-d_{3}\right)}+\frac{\sigma_{32}^{2}}{k_{2}^{0}\left(1-d_{2}\right)}+\frac{\sigma_{31}^{2}}{k_{1}^{0}\left(1-d_{1}\right)}\right] \text {, }
$$

where $k_{i}^{0}$ are interlaminar stiffness values $\left(k_{3}^{0}\right.$ is the transverse stiffness of the material and $k_{2}^{0}, k_{1}^{0}$ are the shear stiffnesses) and $d_{i}$ are the internal damage indicators associated with its fracture mechanics mode (opening, shear and sliding modes). Thermodynamic forces $\left(Y_{d 1}, Y_{d 2}, Y_{d 3}\right)$ are obtained from the derivative of the elastic strain (Eq. 1) with respect to the damage variables:

$$
Y_{d 3}=\frac{1}{2} \frac{\left\langle\sigma_{33}\right\rangle_{+}^{2}}{k_{3}^{0}\left(1-d_{3}\right)^{2}} ; \quad Y_{d 1}=\frac{1}{2} \frac{\sigma_{31}^{2}}{k_{1}^{0}\left(1-d_{1}\right)^{2}} ; \quad Y_{d 2}=\frac{1}{2} \frac{\sigma_{32}^{2}}{k_{2}^{0}\left(1-d_{2}\right)^{2}}
$$


Equivalent thermodynamic force $Y$ is then defined as:

$$
Y=\sup _{\tau<t}\left[Y_{d 3}^{\alpha}+\left(\gamma_{1} Y_{d 1}\right)^{\alpha}+\left(\gamma_{2} Y_{d 2}\right)^{\alpha}\right]^{1 / \alpha}
$$

where $\alpha$ is a material parameter which controls the ratio of the damage under mixed-mode loading conditions and $\gamma_{1}$ and $\gamma_{2}$ are coupling parameters. A damage evolution law is then defined as:

$$
d_{3}=d_{1}=d_{2}=\left[\frac{n}{n+1} \frac{\left\langle\underline{Y}-Y_{0}\right\rangle_{+}}{Y_{C}-Y_{0}}\right]^{n} \quad \text { if } d_{3}<1, d_{3}=d_{1}=d_{2}=1 \text { otherwise }
$$

where $Y_{C}$ is the critical damage energy release rate, $Y_{0}$ is the threshold value and $n$ is the characteristic function of the material where high values correspond to a brittle interface. This damage evolution law is associated with linear elastic fracture mechanics [5]. For pure-mode conditions, when the critical energy release rate stabilizes, we obtain:

$$
G_{c I}^{p}=Y_{C} ; \quad G_{c I I}^{p}=\frac{Y_{C}}{\gamma_{1}} ; \quad G_{c I I I}^{p}=\frac{Y_{C}}{\gamma_{2}} .
$$

And from the derivate we obtain the formula for a mixed-mode loading condition:

$$
\left(\frac{G_{I}}{G_{c I}^{p}}\right)^{\alpha}+\left(\frac{G_{I I}}{G_{c I I}^{p}}\right)^{\alpha}+\left(\frac{G_{I I I}}{G_{c I I I}^{p}}\right)^{\alpha}=1
$$

\section{Experimental Test}

An experimental fracture mechanics test was done to identify the damage interface parameters according to the ASTM test [6]. Several types of experimental tests were devised to determine the material parameters of Mode II, such as: end-notched flexure test (ENF), over-notched flexure test (ONF), end-loaded split test (ELS), internal-notched flexure (INF) and four point end-notched test (FENF) [7]-[9]. In this case, the pure-mode II End-Notched Flexure test (ENF) was chosen. Special specimens were created [6], [10]. Eight plies of prepreg were used for each arm of the specimen. An anti-adhesive ply was inserted in the mid-plane of the specimens to initiate cracking. The geometric properties of the specimens and their attachment are given in Fig. 1 and in Table 1.
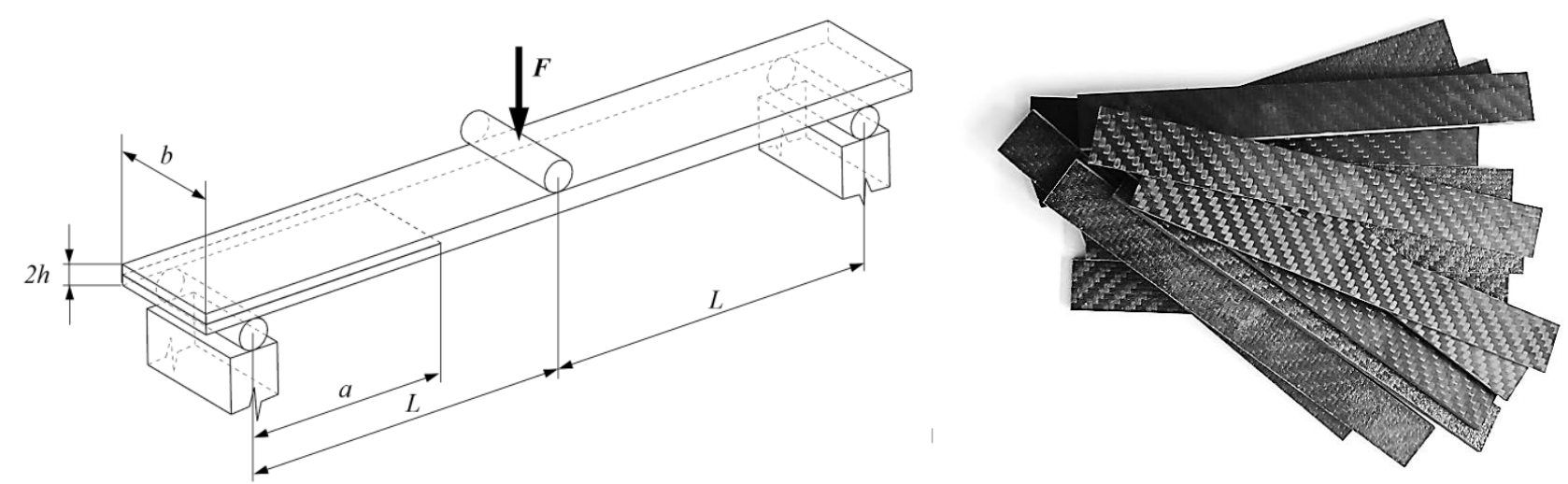

Fig. 1 Diagram of the ENF specimen (left), specimens for experimental measurement (right).

Table 1 Geometrical properties of the specimen

\begin{tabular}{|c|c|l|}
\hline $\mathbf{h}(\mathbf{m m})$ & 0.207 & Thickness of the specimen \\
\hline $\mathbf{b}(\mathbf{m m})$ & 1470 & Density \\
\hline $\mathbf{a}(\mathbf{m m})$ & 55.8 & Initial crack length \\
\hline $\mathbf{l}(\mathbf{m m})$ & 170 & Total length of specimen \\
\hline $\mathbf{L}(\mathbf{m m})$ & 50 & Length between force and support \\
\hline Layout (-) & {$\left[(0)_{4 \mathbf{s}} /(0)_{4 \mathbf{s}}\right]$} & Layout of plies of specimen \\
\hline
\end{tabular}


200 gsm carbon twill (2x2) prepreg GG200t (from 3k T700 Toray fibres and high toughness epoxy matrix DT120) was used for fabrication of the specimens. The mechanical properties of the material are given in Table 2.

Table 2 Mechanical properties of carbon fibre prepreg.

\begin{tabular}{|l|c|l|l|}
\hline$t(\mathrm{~mm})$ & 0.207 & Thickness of ply & \\
\hline$\rho\left(\mathrm{kg} / \mathrm{m}^{3}\right)$ & 1470 & Density & \\
\hline$E_{l}(\mathrm{GPa})$ & 54.8 & Young's Modulus $0^{\circ}$ & acc. to ASTM D 3039 \\
\hline$E_{2}(\mathrm{GPa})$ & 53.7 & Young's Modulus $90^{\circ}$ & acc. to $A$ ASTM D 3039 \\
\hline$E_{3}(\mathrm{GPa})$ & 6.4 & Young's Modulus N90 & acc. to ASTM D 3039 \\
\hline$G_{12}(\mathrm{GPa})$ & 3.12 & In-plane Shear Modulus & acc. to ASTM D 3518 \\
\hline$v_{12}(-)$ & 0.27 & Major Poisson's Ratio & acc. to ASTM D 3039 \\
\hline
\end{tabular}

The experimental tests were conducted on a Zwick-Roell Z050 testing machine at ambient temperature (see Fig. 2). The displacement rate was fixed at $1 \mathrm{~mm} / \mathrm{min}$. Measurements were recorded using a DSLR camera and a high-precision microphone to record initialization of the crack.
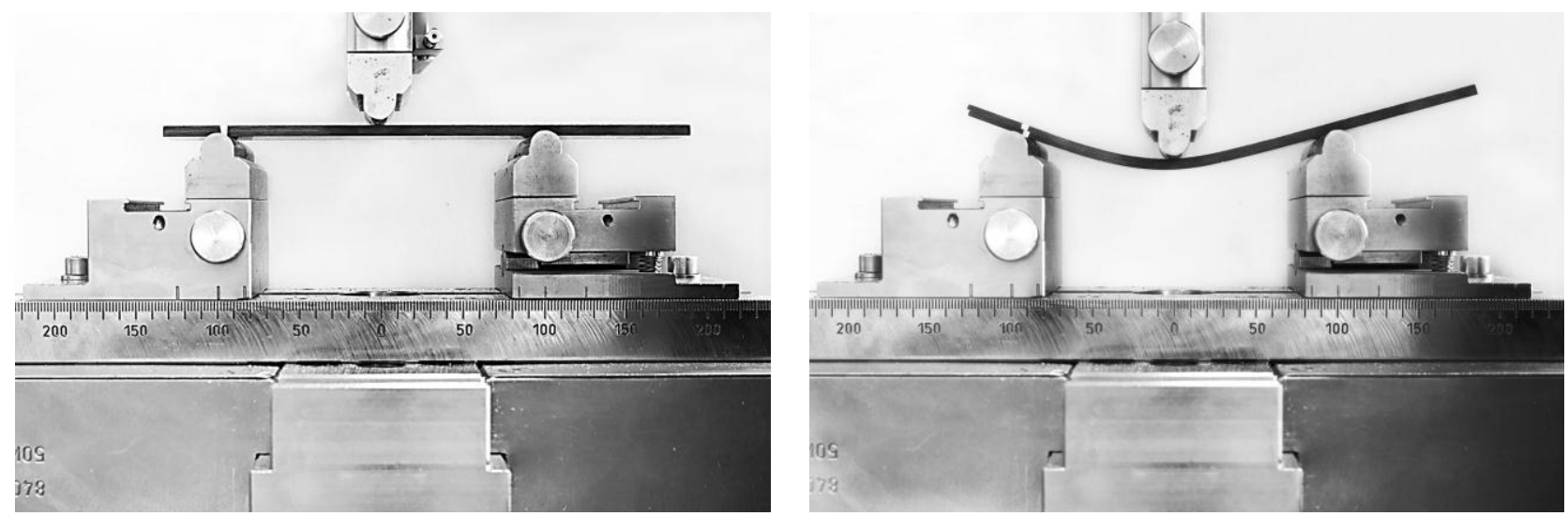

Fig. 2 Experimental test of the ENF specimens

Fourteen specimens were tested with very similar results (see Fig. 3). The average force of the initialization $\left(F_{o_{-} i n i}\right)$ of the crack was reached at $519 \mathrm{~N}$ at displacement $\delta_{o_{-} i n i}=4.1(\mathrm{~mm})$.

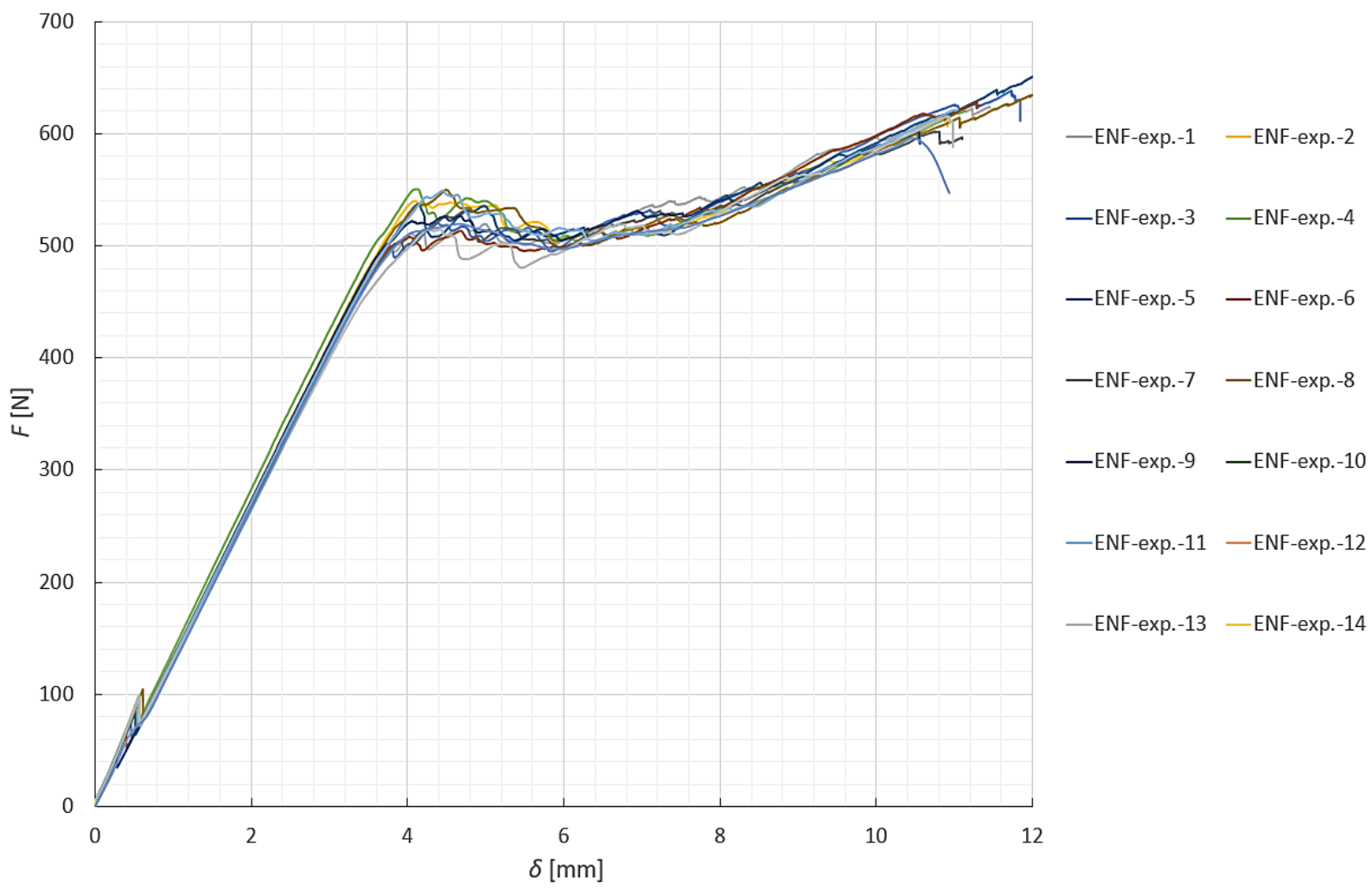

Fig. 3 The force-displacement curves obtained in the ENF test of the CFRP specimens. 


\section{Numerical Simulation}

Mode II delamination crack growth simulation of CFRP composite specimens was done in Siemens Simcenter 3D 12.0.2 finite element software with non-linear solver NX Nastran 401 Multi-Step Nonlinear. A three-dimensional FE model from quadratic CBRICK20 elements and special cohesive T147 elements was created. The FE mesh consisted of 1803 elements for each arm and 602 cohesive elements for the damage interface of the specimen.

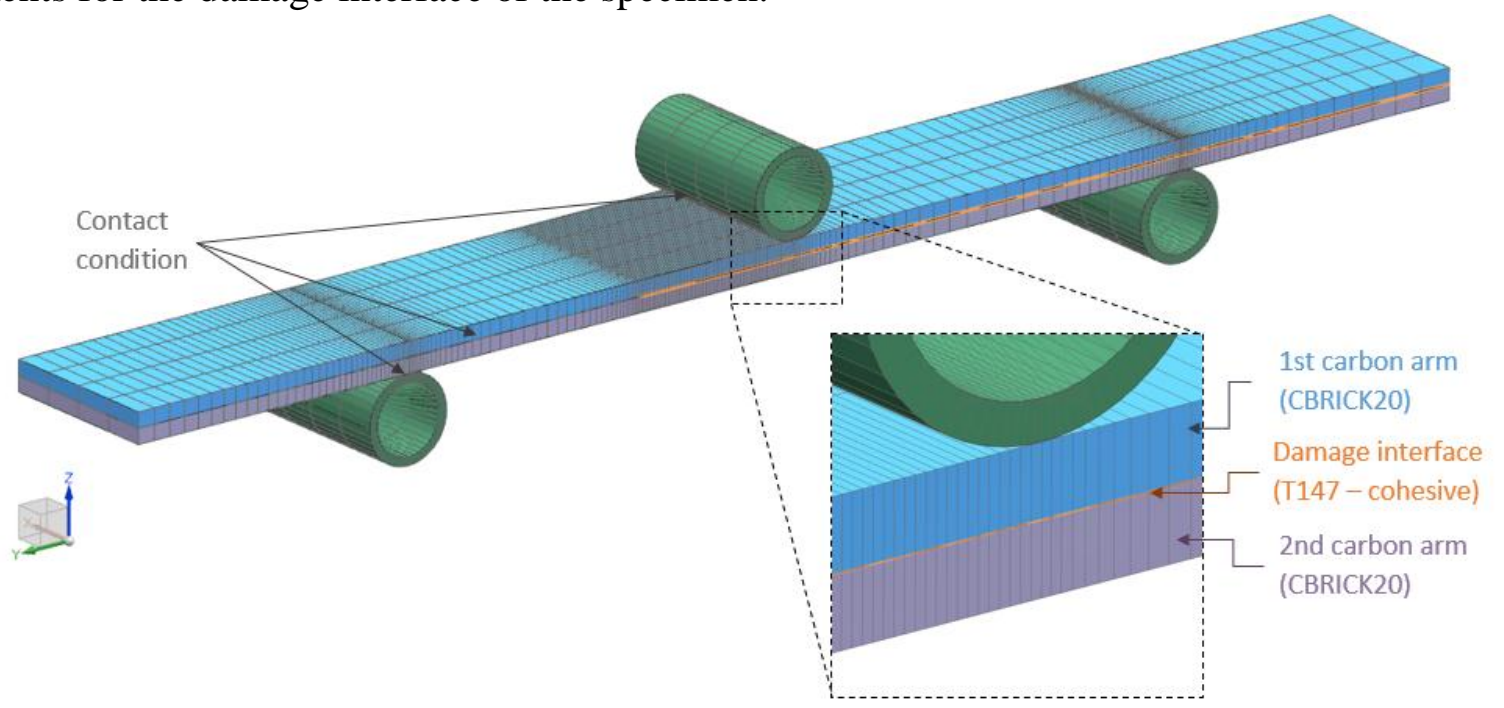

Fig. 4 Experimental test of the ENF specimens

Fitting the Numerical Simulation. The cohesive zone modelling is based on a presumption of a zone of softening ahead of a sharp crack tip in material. Within this zone, the opening is resisted by cohesive tractions [11]. Interface behaviour is defined by a cohesive law that applies the relationship between the interfacial stresses and relative displacements. Many types of the constitutive law for the interfaces were evolved: bi-triangular (the most commonly used), exponential [12], polynomial [13] or trapezoidal [14]. In this case, the bi-triangular model was used (see Fig. 5) and the parameters were identified by fitting the simulation to the experimental results. The fitting process was carried out in three main steps. First the shear stiffness $k_{1}^{0}$ of the interface was found. This parameter affects the rising angle (elastic part) of the chart. Subsequently the point of the maximum load and softening of the delamination of the specimen was found by changing the parameters of the fracture energy $G_{C I I}^{p}$ and thermodynamic force $Y_{O S}$ (area of the first triangle of the stress displacement curve). The fracture toughness $G_{\text {cII_num }}^{p}=1040\left(\mathrm{~J} / \mathrm{m}^{2}\right)$ and initial interface shear stiffness $k_{1}^{0}=7450\left(\mathrm{~N} / \mathrm{mm}^{3}\right)$ was determined to be the most similar.

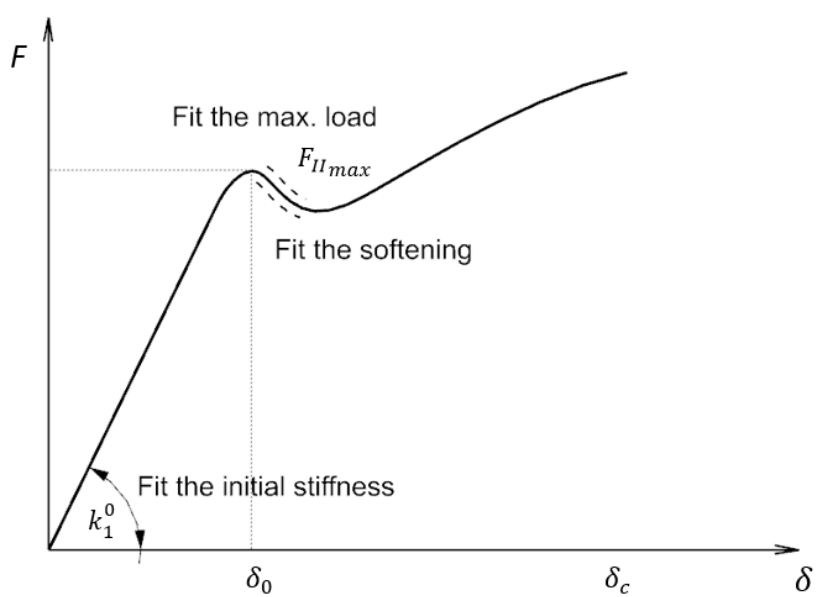

(a)

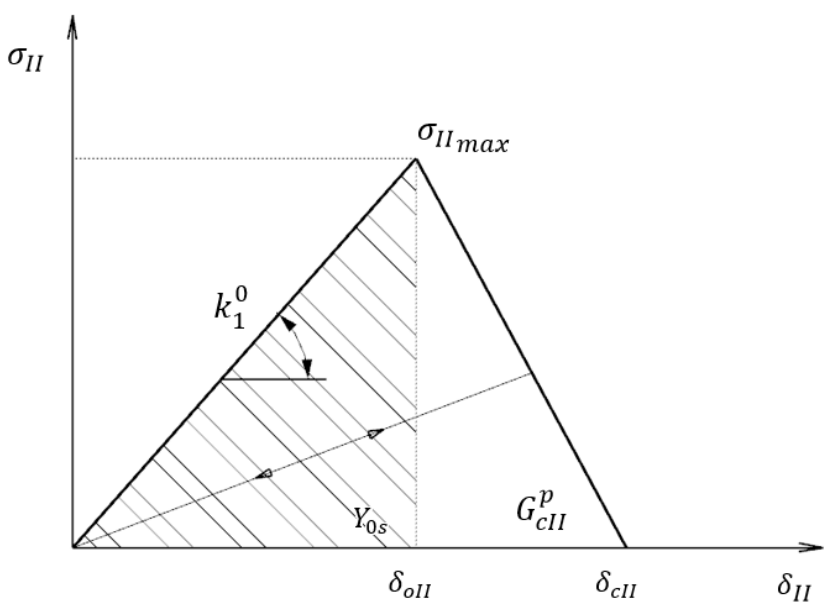

(b)

Fig. 5 The schema of the parameter identification: (a) Structural response, (b) Bi-triangular constitutive model in the interface. 
Results and Discussion. The results from the numerical simulation are given in Fig. 6, where very good agreement with the average results from the experimental measurements (blue line) and analytic values (green lines) can be seen. Where the analytic value of the critical energy release rate $G_{c I I}^{p}\left(\mathrm{~J} / \mathrm{m}^{2}\right)$ was obtained by derivation of the experimental compliance of the specimens (see Eq. 7). The analytic solution on the chart in Fig. 6 shows only the main parts of the damage process (elastic and delamination parts).

$$
G_{c I I}^{p}=\frac{9 F^{2} a^{2}}{16 b^{2} h^{3} E_{x}}=\frac{9 F a^{2} \delta}{2 b\left(3 a^{3}+2 L^{3}\right)}
$$

where:

$$
\delta=\frac{F\left(3 a^{3}+2 L^{3}\right)}{8 E_{x} b h^{3}}
$$

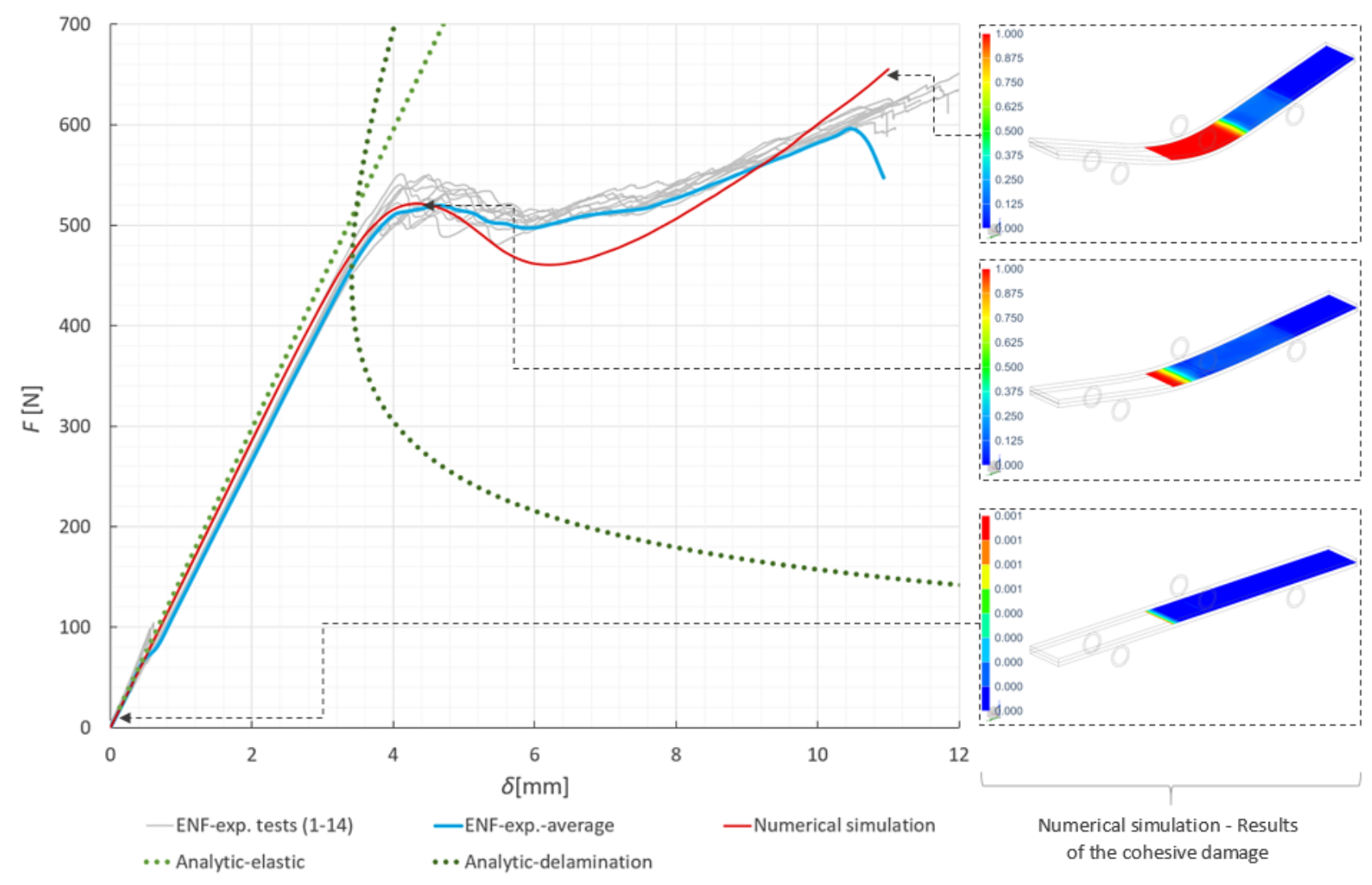

Fig. 6 Force-displacement curve of the ENF test (left); results of the cohesive damage for Mode II. in numerical simulation (right).

\section{Summary}

The experimental measurements of the ENF specimens made from carbon fibre twill prepreg were undertaken according to ASTM standards. The mode II fracture toughness of the CFRP twill carbon fibre laminate was obtained by fitting the results from the experimental tests with the numerical simulation and they correspond with a very good accuracy of up to $4 \%$ (fracture toughness $G_{\text {cII_exp }}^{p}=$ $1082\left(\mathrm{~J} / \mathrm{m}^{2}\right)$ found in the experimental measurement, and in the numerical simulation it was determined to be $G_{c I I \_n u m}^{p}=1040\left(\mathrm{~J} / \mathrm{m}^{2}\right)$. This shows that the chosen methodology is appropriate for determining the parameters.

In future work, the fracture toughness of the same prepreg will be determined for mode I and a mix of modes I/II with a subsequent validation of the resulting data on a more complex composite part using experimental measurements. 


\section{Acknowledgement}

This article has been prepared under project LO1502 'Development of the Regional Technological Institute' under the auspices of the National Sustainability Programme I of the Ministry of Education of the Czech Republic aimed at supporting research, experimental development and innovation.

\section{References}

[1] T. Ramesh and S. Chandra V., Damage and Failure of Composite Materials, vol. 2012. Cambridge: Cambridge University Press.

[2] V. K. Goyal, N. R. Jaunky, E. R. Johnson, and D. R. Ambur, 'Intralaminar and interlaminar progressive failure analyses of composite panels with circular cutouts', Composite Structures, vol. 64, no. 1, pp. 91-105, Apr. 2004.

[3] L. N. Phillips, Design with Advanced Composite Materials. Ashgate Publishing, Limited, 1989.

[4] O. Allix and P. Ladevèze, 'Interlaminar interface modelling for the prediction of delamination', Composite Structures, vol. 22, no. 4, pp. 235-242, Jan. 1992.

[5] O. Allix and A. Corigliano, 'Modeling and simulation of crack propagation in mixed-modes interlaminar fracture specimens', Int J Fract, vol. 77, no. 2, pp. 111-140, Jun. 1996.

[6] A. Standard, 'D7905/D7905M-14', Standard Test Method for Determination of the Mode II Interlaminar Fracture Toughness of Unidirectional Fiber-Reinforced Polymer Matrix Composites, 2014.

[7] C. Fan, P.-Y. B. Jar, and J.-J. R. Cheng, 'Internal-Notched Flexure Test for Measurement of Mode II Delamination Resistance of Fibre-Reinforced Polymers', Journal of Composites, 2013. [Online].

[8] R. H. Martin and B. D. Davidson, 'Mode II fracture toughness evaluation using four point bend, end notched flexure test', Plastics, Rubber and Composites, vol. 28, no. 8, pp. 401-406, Aug. 1999.

[9] H. Wang and T. Vu-Khanh, 'Use of end-loaded-split (ELS) test to study stable fracture behaviour of composites under mode II loading', Composite Structures, vol. 36, no. 1, pp. 7179, Sep. 1996.

[10] P. Davies, C. Moulin, H. H. Kausch, and M. Fischer, 'Measurement of GIC and GIIC in carbon/epoxy composites', Composites Science and Technology, vol. 39, no. 3, pp. 193-205, 1990.

[11] S. R. Hallett and P. W. Harper, '2 - Modelling delamination with cohesive interface elements', in Numerical Modelling of Failure in Advanced Composite Materials, P. P. Camanho and S. R. Hallett, Eds. Woodhead Publishing, 2015, pp. 55-72.

[12] S. Abrate, J. F. Ferrero, and P. Navarro, 'Cohesive zone models and impact damage predictions for composite structures', Meccanica, vol. 50, no. 10, pp. 2587-2620, Oct. 2015.

[13] U. Zerbst, M. Heinimann, C. D. Donne, and D. Steglich, 'Fracture and damage mechanics modelling of thin-walled structures - An overview', Engineering Fracture Mechanics, vol. 76, no. 1, pp. 5-43, Jan. 2009.

[14] V. Tvergaard and J. W. Hutchinson, 'The relation between crack growth resistance and fracture process parameters in elastic-plastic solids', Journal of the Mechanics and Physics of Solids, vol. 40, no. 6, pp. 1377-1397, Aug. 1992. 